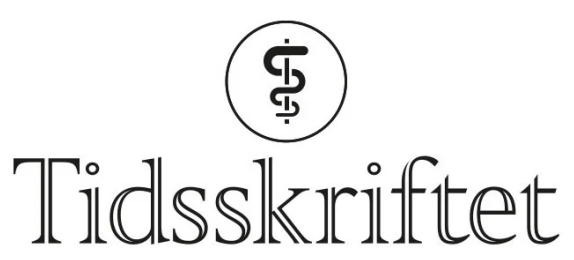

DEN NORSKE LEGEFORENING

\title{
En kvinne i 6o-årene med epilepsi og synkope
}

NOE Å LARE AV

\author{
JANA MIDELFART-HOFF \\ jmid@helse-bergen.no \\ Nevrologisk avdeling \\ Haukeland universitetssjukehus \\ og \\ VID vitenskapelige høgskule \\ Fakultet for helsefag \\ Bergen \\ Jana Midelfart-Hoff er spesialist i nevrologi og overlege. \\ Forfatteren har fylt ut ICMJE-skjemaet og oppgir ingen interessekonflikter.
}

\section{GREGORZ GRADEK}

Hjerte- og lungesenteret

Bergen

Gregorz Gradek er spesialist i indremedisin og i hjertesykdommer og er privatpraktiserende. Forfatteren har fylt ut ICMJE-skjemaet og oppgir ingen interessekonflikter.

\section{ØYSTEIN WENDELBO}

Hjerteavdelingen

Haukeland universitetssjukehus

og

VID vitenskapelige høgskule

Fakultet for helsefag

Bergen

Øystein Wendelbo er spesialist i infeksjonssykdommer og overlege.

Forfatteren har fylt ut ICMJE-skjemaet og oppgir ingen interessekonflikter.

\section{BERNT ANDREAS ENGELSEN}

Nevrologisk avdeling

Haukeland universitetssjukehus

og

Universitetet i Bergen

Bernt Andreas Engelsen er spesialist i nevrologi og professor emeritus ved Universitetet i Bergen.

Forfatteren har fylt ut ICMJE-skjemaet og oppgir ingen interessekonflikter. 


\section{En kvinne i 6o-årene hadde fătt diagnosen epilepsi rundt 30 år tidligere, og sykdommen var godt stabilisert ved hjelp av medisiner. På kontroll ved nevrologisk poliklinikk fortalte hun om et nylig anfall, og dosen med epilepsimedisin ble økt. Årsaken viste seg imidlertid å være en helt annen.}

En kvinne i 6o-årene hadde 30 år før det aktuelle vært innlagt på nevrologisk avdeling, etter det som i journalen ble beskrevet som et meget overbevisende krampeanfall med klare epileptiske forandringer på elektroencefalografi (EEG). Forut for dette var hun frisk og hadde ingen kjente sykdommer. Pasienten startet med epilepsimedisinen karbamazepin (Tegretol) i tabletter $300 \mathrm{mg} \times 3$. For å se om det var strukturell patologi som var årsak til epilepsien ble det noen år senere utført magnetresonanstomografi (MR). Denne avdekket patologisk høysignal i høyre hippocampusområde, tolket som høyresidig sklerose av hippocampus.

Betegnelsen hippocampus brukes om et område i hjernen som ligger basalt i hver av tinninglappene. Dets form kan minne om en liten sjøhest, derav navnet (gr. hippokampos= sjøhest). Hippocampus spiller en vesentlig rolle for læring og korttidshukommelse og finnes hos alle virveldyr. Sklerose av dette området er assosiert med behandlingsrefraktær epilepsi hos voksne mennesker. I tillegg til å være en årsak til epilepsi kan også langvarige epileptiske anfall føre til slik sklerosering. Hippocampus er også sårbar for sykdommer og skader, slik som traumatiske hjerneskader eller inflammatoriske tilstander (1) $)$.

Pasienten ble fulgt jevnlig opp ved nevrologisk poliklinikk og var klinisk i god form, selv om ny EEGundersøkelse fem år etter første innleggelse fremdeles viste epileptiske forandringer. Hun fortsatte med karbamazepin fem år til før medikamentet, etter avtale med nevrolog, ble seponert grunnet mange års anfallsfrihet og fordi pasienten opplevde mulige bivirkninger som tretthet og kognitiv treghet. Året etter at hun hadde sluttet med medisin, kom hun på nytt til nevrologisk avdeling etter et anfall, og det ble startet opp med karbamazepintabletter 3 oo $\mathrm{mg} \times 3$ igjen. 16 år senere ble karbamazepin seponert til fordel for okskarbamazepin (Trileptal) i tabletter $450 \mathrm{mg} \times 2$ for å få en gunstigere bivirkningsprofil, ikke minst bedre lipidprofil, da hun hadde fått påvist forhøyet kolesterol. Mange pasienter med epilepsi trenger livslang medikamentell behandling. Det er vist at langvarig bruk av karbamazepin øker risikoen for vaskulær sykdom (også kardiovaskulær sykdom) blant annet gjennom raskere utvikling av aterosklerose (르). Karbamazepin kan også gi hjertearytmier (3). Okskarbamazepin er beskrevet å ikke ha disse bivirkningene i samme grad (3), og det ble derfor oppfattet som et gunstig alternativ for denne pasienten.

To år etter medikamentendringen kom pasienten til kontroll på nevrologisk poliklinikk. Hun fortalte da om en episode hvor hun hadde mistet bevisstheten mens hun stod og laget kaffe ved kjøkkenbenken. Hun var usikker på hvor lenge hun hadde vart borte, men beskrev det som om det varte noen sekunder. Da hun kom til seg selv på gulvet, oppdaget hun at hun hadde sølt kaffe på buksen. På mistanke om ikke-kontrollert epilepsi og etter måling av serumspeil, som viste nivåer $i$ nedre terapeutiske område, ble dosen av okskarbamazepin økt til $500 \mathrm{mg} \times 2$.

Når pasienter med stabil epilepsi får gjennombruddsanfall, er det viktig å vurdere mulige utløsende faktorer. Det mest opplagte er å se på medisineringen. En norsk studie viste at over $20 \%$ av de inkluderte pasientene tidvis glemte å ta medisinen, mens $19 \%$ ikke fulgte behandlingsplanen (4.). Å spørre målrettet om hvordan pasienten tar medisinen og om doser ofte uteglemmes, er derfor viktig. Måling av serumspeil kan være til god hjelp, også som et pedagogisk virkemiddel i dialogen med pasienten. Det var gjort hos denne pasienten, der hun for begge medisinene lå innenfor det terapeutiske vinduet.

Dernest må man se om andre forhold har endret seg. Interkurrent sykdom eller endring i kjent hjernesykdom med epileptogene egenskaper (for eksempel vekst av hjernesvulst) vil kunne forverre anfallene. Mye stress, lite søvn og menstruasjon er også kjente 
anfallsutløsende årsaker (5). Bildediagnostikk bør utføres hvis anfallene har endret karakter eller er blitt hyppigere etter en stabil fase.

Det kan ofte være nødvendig å legge til et nytt medikament for å bedre anfallskontroll, eventuelt endre medisineringen helt. I første omgang vil man imidlertid som regel velge å justere dosen, slik som hos denne pasienten.

Da pasienten kom til ny kontroll ved nevrologisk poliklinikk noen måneder senere, fortalte hun om et nytt anfall. Igjen skjedde dette på morgenen etter at hun hadde stelt seg og skulle til å lage kaffe. Hun var i ferd med å sette seg ned på en stol da hun følte at alt forsvant under henne, hun seg sammen og falt ned på gulvet. Mannen kom umiddelbart til, fant henne liggende på gulvet og mente at hun var borte i rundt ti sekunder. Det var ingen observerte kramper eller vannavgang, men hun hadde snorkende respirasjon.

Like før denne episoden hadde det vart gjort en cerebral MR-undersøkelse i regi av fastlegen på grunn av mye hodepine. Denne påviste et ganske ferskt hjerneinfarkt i venstre del av lillehjernen. Pasienten var derfor blitt henvist til privatpraktiserende kardiolog for utredning av mulige kardiale årsaksforhold.

På kontrollen ved nevrologisk poliklinikk ble den beskrevne anfallsepisoden oppfattet å vare relatert til hennes epilepsi og muligens også det nye hjerneinfarktet. Medisineringen ble holdt uendret fra sist kontroll.

Studier har vist en insidens av epilepsi etter hjerneslag på 2,5\%, med en fordobling i løpet av fem år $(\underline{6}, 7.7$. . Tilstanden er hyppigere hos eldre pasienter og defineres som to eller flere tilbakevendende anfall mer enn fire uker etter gjennomgått hjerneslag (7.). Infarktets størrelse ser ut til å være en risikofaktor $(\underline{6}, 7$.$) , noe som kan forklare at hjerneslag i fremre$ del av hjernens kretsløp i større grad ser ut til å føre til epilepsi enn hjerneslag i bakre kretsløp, fordi det involverer større deler av hjernen (요). Det ser også ut til at affeksjon av temporallappene øker risikoen for utvikling av senere epilepsi (9.).

Pasienten hadde dermed «dobbel» grunn til å fortsette med anfallsmedisinering, både epilepsien og nå det nye hjerneinfarktet. Hjerneinfarktet hadde sannsynligvis vært "stumt», det er svært sjelden hjerneslag debuterer med kramper eller epileptiske anfall. Ved påvist hjerneinfarkt er det imidlertid viktig å igangsette utredning og starte med tilpasset sekundærprofylakse for å redusere risikoen for nytt infarkt.

Høsten samme år var pasienten til vurdering hos privatpraktiserende kardiolog. Elektrokardiografi (EKG) viste sinusrytme 71 slag per minutt, $P Q-$-tid < o,14 s (referanseområde o,12-o,21), QRS-bredde 96 ms (<120) og ST-segment beskrevet som innenfor normale verdier (figur 1). På ekkokardiografi, inkludert tredimensjonal ekkokardiografi, fant man normal beliggenhet og størrelse av hjertet, normal bevegelse av hjerteklaffene og hjertekammerveggene samt normale blodstrømshastigheter gjennom hjertets ulike klaffer. 

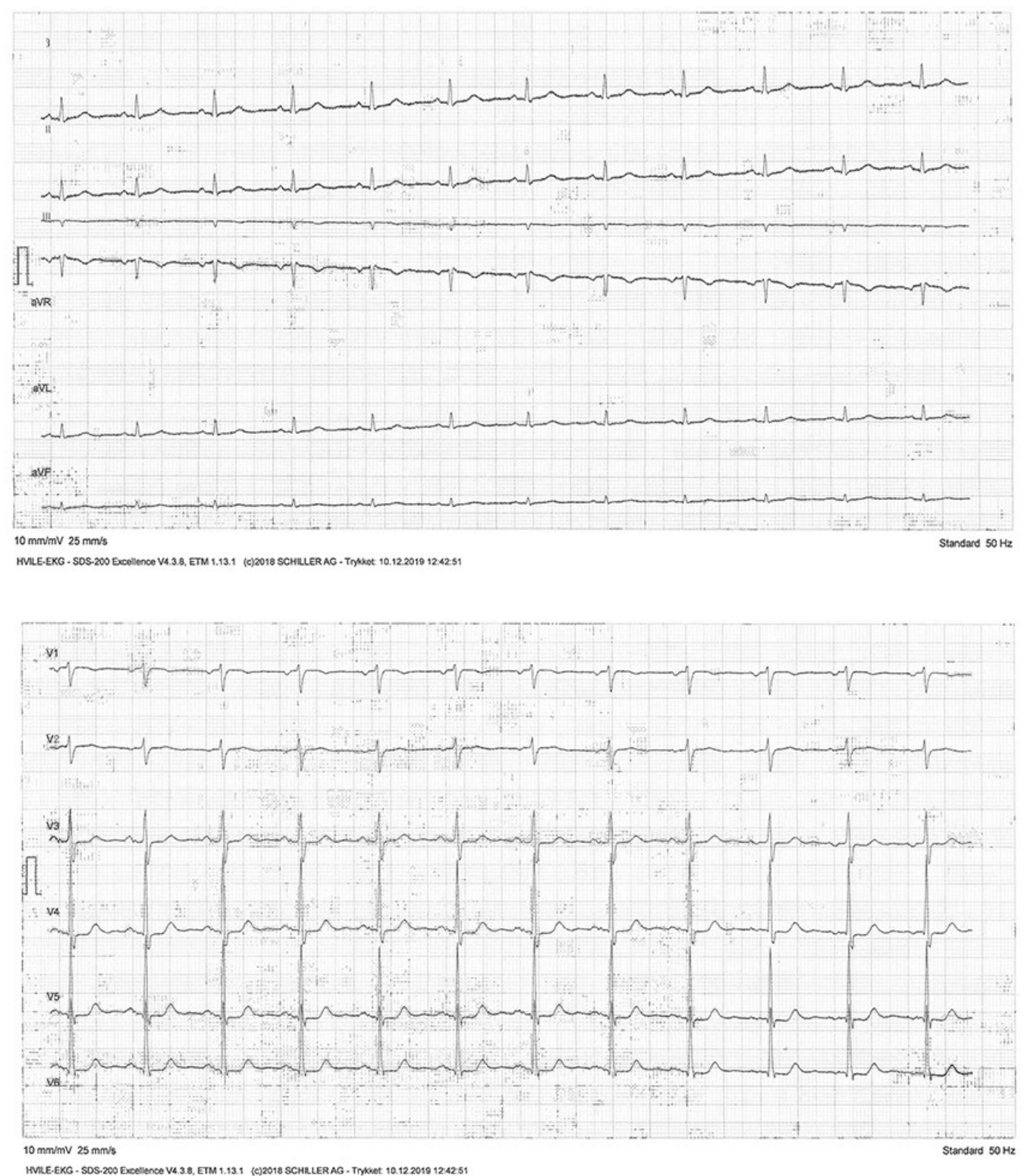

Figur 1 EKG tatt i hvile viser sinusrytme og normal elektrisk akse i alle de 12 avledningene. Da pasienten påfølgende døgn skulle levere inn 24-timers EKG-registrering (Holter-monitorering), fortalte ektefellen at pasienten samme morgen plutselig hadde falt sammen noen sekunder under frokosten. Hun var bevisstløs, og det var heller ikke nå observert kramper, tungebitt eller vannavgang.

Kardiologen gikk gjennom registreringen og fant da sinusrytme gjennom døgnet før. Man så at hun på gitte tidspunkt på morgenen fikk noen sekunder med AV-blokk 2:1 før hun fikk total AV-blokk uten nodal erstatningsrytme og asystoli med 30 sekunders varighet. Deretter kom igjen tre hjerteslag med normale QRS-komplekser (figur 2). Kardiologen oppfattet tilstanden som sannsynlig AV-blokk grad 1 med lang PQ-tid. Det var ikke registrert annen arytmi, heller ikke supraventrikulcer ekstrasystole (SVES) eller ventrikulcer ekstrasystole (VES) av betydning. 


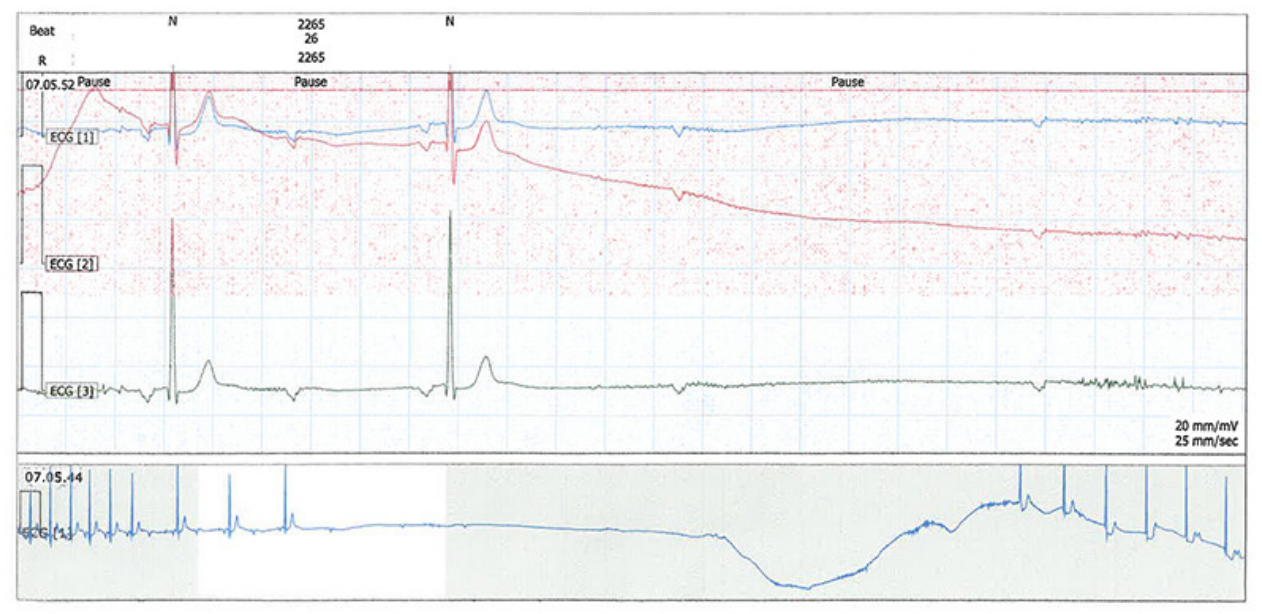

Figur 2 24-timers EKG på det tidspunktet pasienten ble bevisstløs viser bortfall av QRSkomplekser, etterfulgt av total AV-blokk uten nodal erstatningsrytme og asystoli med 30 sekunders varighet, sannsynlig AV-blokk grad 1 med lang PQ-tid.

Pasienten ble samme dag innlagt på hjerteavdelingen, hvor man fant indikasjon for permanent pacemaker. Pasienten ble etter prosedyren utskrevet i god allmenntilstand.

Ved kontroll av pacemakeren et halvt år senere var pasienten i fin form og hadde ikke hatt flere episoder med bevissthetstap. EKG-unders $ø$ kelse viste normale funn, sinusrytme og velfungerende pacemaker. På direkte spørsmål fortalte pasienten at hun gjennom mange år hadde hatt episoder med synkope/ncersynkoper på morgenen. Hun brukte fortsatt okskarbamazepin fast, nå redusert igjen til dosen hun hadde hatt tidligere, $450 \mathrm{mg} \times 2$.

\section{Diskusjon}

Pasienter med førstegangs bevissthetstap henvises ofte til nevrolog med spørsmål om epilepsi. På nevrologiske poliklinikker er pasienter med gjentatte synkoper gjengangere, ofte etter at annen utredning er utført, men ikke alltid. En viktig differensialdiagnose er kardiale synkoper. Hovedårsaken til kardiale synkoper er arytmier, men kan også være betinget i strukturell hjertesykdom eller sykdom i de kardiopulmonale blodårene (므). Årsaken til bevissthetstap kan ofte avklares gjennom grundig sykehistorie med støtte fra komparentopplysninger, så også her ser man hvor viktig en god anamnese er som grunnlag for videre diagnostikk. Synkoper oppstått under anstrengelse eller i oppreist stilling, med akutt inntreden og med spontan, rask helbredelse peker ofte i retning av kardiale synkoper, særlig hvis anamnesen viser akutt hjertedød i familien fra tidligere eller kjent hjertesykdom i tillegg (므).

Det er imidlertid ikke alltid så enkelt å avgrense epileptiske anfall fra kardialt betingede synkoper. Mens man tidligere antok at kardiale synkoper hovedsakelig skjedde under fysisk aktivitet, tyder studier imidlertid på at de også kan oppstå som plutselig, uventet bevissthetstap uten foranledning eller komme som konvulsive kramper under søvn (1ㅡ). Årsaken til og behandlingen av synkoper kan derfor være krevende og fordre tverrfaglig samarbeid, noe som gjenspeiles i European Society of Cardiology sine retningslinjer for diagnostikk og behandling av synkope fra 2018, utarbeidet med bred deltagelse av

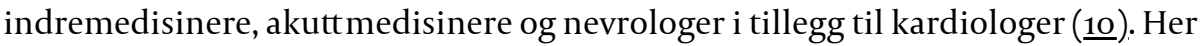
fremheves også at pasienten fortrinnsvis bør vurderes og stratifiseres for risiko i en bredere faglig kontekst, gjerne i form av dedikerte, tverrfaglige synkopeteam. Dette skjer i dag allerede delvis i norske akuttmottak, hvor svært mange pasienter avklares av mottakslege, som ved behov involverer andre spesialiteter. I en poliklinisk setting vil dette ofte være mer komplisert å få til. 
Ved kjent epilepsi kan det være nærliggende å tenke at det som ellers ville blitt oppfattet som en synkope, er epilepsirelatert. Symptomer eller tegn som peker i retning av epileptisk årsak er tungebitt, abnorm oppførsel, postiktal konfusjon og ubehag i forkant (prodromal déjà vu eller jamais vu) (12).

Pasienter med kronisk epilepsi har høy forekomst av komorbiditet, blant annet av autoimmune sykdommer, hjertesykdommer og psykiske lidelser. De har også økt risiko for tidlig død, ofte satt i relasjon til begrepet plutselig, uventet død ved epilepsi (sudden unexpected death in epilepsy, SUDEP) (13,14.), som er definert som «uventet, plutselig ikketraumatisk, ikke relatert til drukning, død hos person med epilepsi, observert eller ikke observert, hvor autopsi i etterkant ikke avdekker anatomisk eller toksikologisk årsak til $\mathrm{d} ø \mathrm{~d} »(15)$. Risikofaktorer knyttet til denne typen plutselig, uventet $\mathrm{d} ø \mathrm{~d}$ ser ut til å være hyppige generaliserte anfall, yngre alder, dårlig etterlevelse (compliance) av antiepileptiske medisiner og dårlig anfallskontroll generelt $(\underline{16}, \underline{17})$. En annen fryktet og potensielt dødelig tilstand hos pasienter med epilepsi er status epilepticus, definert som mer enn 30 minutter med kontinuerlige kramper eller multiple anfall uten at pasienten gjenvinner bevisstheten innimellom (묘).

Både plutselig, uventet død ved epilepsi og status epilepticus er viktige årsaker til anfallsrelaterte dødsfall og viktig at behandlende lege kjenner til, men studier tyder på at de utgjør en liten andel av totale dødsårsaker hos pasienter med epilepsi (13,14). Hovedårsakene til for tidlig død er somatiske tilstander som kreft og kardiovaskulær/cerebrovaskulær sykdom, og studier peker på at dette ofte overses $(\underline{19}, \underline{20})$.

Studier gjort hos pasienter med kronisk epilepsi har vist forstyrrelser i hjertefrekvens,

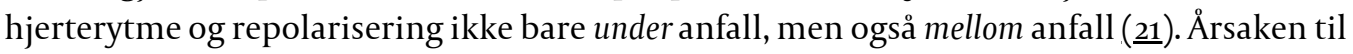
dette kan være ionekanalforstyrrelser, enten som en følgetilstand av epilepsien eller som en arvelig variant, som både fører til epilepsi og til rytmeforstyrrelse (ي1).

Slik vi ser det, var utgangspunktet hos denne pasienten hennes epilepsi, relatert til sklerosen som ble påvist i hippocampus og med overbevisende EEG-funn. Deretter utviklet hun en hjerterytmeforstyrrelse, som hennes mangeårige bruk av antiepileptika (karbamazepin) kan ha bidratt til. I tillegg er det funnet at hippocampussklerose i seg selv

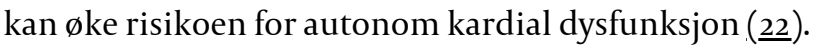

Hos en pasient med velregulert epilepsi over mange år som plutselig får gjentatte anfall på nytt, bør man være ekstra årvåken for andre årsaker enn epilepsien. I etterpåklokskapens lys burde nok dette ha vært vurdert hos denne pasienten ved den andre kontrollen etter medikamentendringen. Imidlertid kan dette i en travel poliklinisk hverdag ha blitt tilslørt av at pasienten på det tidspunktet hadde gjennomgått et hjerneinfarkt, som jo gir økt risiko for epilepsi i etterkant. I tillegg lå det en erkjennelse av at pasientens tilstand var ustabil, ettersom hun ble innkalt til hyppigere kontroller enn dersom hun hadde vært stabil.

Forfatterne vil likevel understreke at når pasienter med tidligere stabil epilepsi får vedvarende forverring og $\varnothing \mathrm{kt}$ anfallsfrekvens, bør man ha lav terskel for å lete etter andre årsaker. I lys av kunnskapen om at både epilepsi i seg selv, men også behandlingen med antiepileptika, kan utløse kardiale arytmier, bør dette stå høyt oppe på den differensialdiagnostiske listen og terskelen være tilsvarende lav for å vurdere det som en mulighet og henvise videre til kardiologisk utredning.

Pasienten har gitt samtykke til at artikkelen blir publisert. Artikkelen er fagfellevurdert.

1. Walker MC. Hippocampal sclerosis: Causes and prevention. Semin Neurol 2015; 35: 193-200. [PubMed][CrossRef] 
2. Chuang YC, Chuang HY, Lin TK et al. Effects of long-term antiepileptic drug monotherapy on vascular risk factors and atherosclerosis. Epilepsia 2012; 53: 120-8.

3. Svendsen T, Alfstad KÅ, Lossius MI et al. Langtidsbivirkninger av antiepileptika. Tidsskr Nor Legeforen 2016; 136:324-7. [PubMed][CrossRef]

4. Henning O, Lossius MI, Lima M et al. Refractory epilepsy and nonadherence to drug treatment. Epilepsia Open 2019; 4: 618-23. [PubMed][CrossRef]

5. Nakken KO, Refsland G, Lillestølen KM et al. Anfallsutløsende faktorer ved epilepsi-hva mener pasientene? Tidsskr Nor Lægeforen 2005; 125: 2172-4. [PubMed]

6. Lossius MI, Rønning OM, Mowinckel P et al. Incidence and predictors for post-stroke epilepsy. A prospective controlled trial. The Akershus stroke study. Eur J Neurol 2002; 9:365-8. [PubMed] [CrossRef]

7. Lossius MI, Rønning OM, Gjerstad L. Epilepsi etter hjerneslag. Tidsskr Nor Lægeforen 2004; 124: 620-2. [PubMed]

8. Pande SD, Lwin MT, Kyaw KM et al. Post-stroke seizure-Do the locations, types and managements of stroke matter? Epilepsia Open 2018;3:392-8. [PubMed][CrossRef]

9. Keller L, Hobohm C, Zeynalova S et al. Does treatment with t-PA increase the risk of developing epilepsy after stroke? J Neurol 2015; 262: 2364-72. [PubMed][CrossRef]

10. Brignole M, Moya A, de Lange FJ et al. 2018 ESC Guidelines for the diagnosis and management of syncope. Eur Heart J 2018; 39: 1883-948. [PubMed][CrossRef]

11. Moya A, Sutton R, Ammirati F et al. Guidelines for the diagnosis and management of syncope (version 2009). Eur Heart J 2009;30: 2631-71. [PubMed][CrossRef]

12. Sheldon R, Rose $S$, Ritchie D et al. Historical criteria that distinguish syncope from seizures. J Am Coll Cardiol 2002; 40:142-8. [CrossRef]

13. Nakken KO. Epilepsi - mer enn anfall. Tidsskr Nor Legeforen 2019; 139. doi:10.4045/tidsskr.19.0149. [PubMed][CrossRef]

14. Gaitatzis A, Carroll K, Majeed A et al. The epidemiology of the comorbidity of epilepsy in the general population. Epilepsia 2004; 45:1613-22. [PubMed][CrossRef]

15. Shankar R, Donner EJ, McLean B et al. Sudden unexpected death in epilepsy (SUDEP): what every neurologist should know. Epileptic Disord 2017;19:1-9. [PubMed][CrossRef]

16. Verducci C, Hussain F, Donner E et al. SUDEP in the North American SUDEP Registry. The full spectrum of epilepsies. Neurology 2019; 93: e227-36. [PubMed][CrossRef]

17. Sveinsson O, Andersson T, Mattsson P et al. Clinical risk factors in SUDEP. A nationwide population-based case-control study. Neurology 2020; 94: e419-29. [PubMed][CrossRef]

18. Cloyd J, Hauser W, Towne A et al. Epidemiological and medical aspects of epilepsy in the elderly. Epilepsy Res 2006; 68 (Suppl 1):39-48. [PubMed][CrossRef]

19. Keezer MR, Bell GS, Neligan A et al. Cause of death and predictors of mortality in a communitybased cohort of people with epilepsy. Neurology 2016; 86: 704-12. [PubMed][CrossRef]

20. Smith PE. Epilepsy: mimics, borderland and chameleons. Pract Neurol 2012; 12: 299-307. [PubMed] [CrossRef]

21. Li MCH, O'Brien TJ, Todaro M et al. Aquired cardiac channelopathies in epilepsy: Evidence, mechanisms, and clinical significance. Epilepsia 2019; 6o: 1753-67. [PubMed][CrossRef]

22. Koseoglu E, Kucuk S, Arman F et al. Factors that affect interictal cardiovascular autonimic dysfunction in temporal lobe epilepsy: role of hippocampal sclerosis. Epilepsy Behav 2009; 16: 617-21. [PubMed][CrossRef]

Publisert: 24. januar 2022. Tidsskr Nor Legeforen. DOI:10.4045/tidsskr.21.0152

Mottatt 27.6.2021, godkjent 28.9.2021.

Publisert under åpen tilgang CC BY-ND. Lastet ned fra tidsskriftet.no 26. april 2023. 